\title{
THE USE OF FABRICS TO IMPROVE THE ACOUSTIC ABSORPTION: INFLUENCE OF THE WOVEN FABRIC THREAD DENSITY OVER A NONWOVEN
}

\author{
Pilar Segura-Alcaraz², Jorge Segura-Alcaraz ${ }^{1}$, Ignacio Montava ${ }^{2}$, Marilés Bonet-Aracil*
}

1Dpto. de Mecánica de los Medios Continuos y Teoría de Estructuras. Universitat Politècnica de Valencia. Alcoy. Spain. ${ }^{2}$ Dpto. de Ingeniería Textil y Papelera. Universitat Politècnica de Valencia. Universitat Politècnica de Valencia. Alcoy. Spain

*E-mail: maboar@txp.upv.es

\begin{abstract}
:
Noise is frequently unnoticed, but it is one of the causes of unhealth for human beings reducing people's quality of life. There are many materials that can be considered as acoustic absorbents. Textiles can be used to both improve the acoustic quality of and to decorate the room where they have been placed. In this study, we used some fabrics with 15, 20 and 30 ends $/ \mathrm{cm}$ and 15, 20 and 30 picks $/ \mathrm{cm}$. The acoustic absorption coefficient was measured when the fabric was added as a resistive layer on top of a nonwoven made of polyester fiber. Results evidence that these fabrics can be efficiently used to modify the acoustic absorption of the nonwoven. Sound absorption coefficients measured via the impedance tube method show that these modifications occur. The results show how it is possible to improve the acoustic characteristics of a simple nonwoven to obtain sound absorption coefficients close to values of 1 at different frequencies by choosing a fabric with the appropriate combination of warp and weft count.
\end{abstract}

\section{Keywords:}

Acoustic, fabric, warp, weft, nonwoven

\section{Introduction}

Nowadays, noise is considered unhealthy and its presence reduces the quality of life. Thus, it is considered, among others, a cause of discomfort for human beings. In order to reach as much comfort in rooms as possible, different kinds of actuations can be implemented: isolation or conditioning. Some developed countries have published their own standards depending on the activity given to the room, such as NTP 503 [1]. which describes the acoustic comfort for offices and how is it possible to achieve it. In order to obtain the optimal acoustic conditioning, the acoustic energy reflected by the limits of the room must be minimum.

The sound absorption is the phenomenon by which a material or structure absorbs some of the sound energy incident thereon. The term "acoustic material" is used for materials produced specifically to provide high levels of absorption [2].

The use of synthetic vitreous fiber wools like rock wool, glass wool, or slag wool to absorb noise is widely spread in construction or other applications which require acoustic isolation. Handling textiles made of mineral wools like rock wool is directly related with some leakage of those fibers. Furthermore, contact dermatitis can be produced by the contamination of the skin by direct, indirect contact, or deposition of airborne fibers [3].

Lately, concern about respect for nature has been increasing and the use of environmentally sustainable materials is one of the desirable aspects in design. From this point of view, the polyester fiber-based textiles have some advantages such as: - low areal density
- flexibility and ability to adapt to coat elements of all shapes
- easy cleaning and durability
- excellent aesthetic features

The textile materials more frequently used for acoustic purposes are generally nonwovens known as "wools". There are numerous studies related with the use of these materials, [4] focused on finding a model of sound propagation through them $[5,6]$ or on describing acoustic properties of nonwovens made of different fibers [7-9] and with different physical parameters $[10,11]$. There are also several patents related with the use of nonwovens in sound absorption applications [12-15].

Since 1949, perforated panels have been used and developed; [16] however, perforated products have been merely used as a coating protector of the fibrous materials [17]. D.Y. Maa [18] introduces the microperforated panels theory. When a material shows the lower size of the perforation, it will present a higher resistance to the sound to go through because of the energy loss due to viscous effect. They have demonstrated to be the best absorbent resonator despite showing a range of frequencies not wide enough to be used in practical applications. Lately, new developments were obtained in order to improve the range of absorbed frequencies [19-28]. Some of them were patented [29-32].

One of the disadvantages of using microperforated panels is the cost of performing micro perforations. With the use of knitted or woven structures, the size, shape and the number of micro perforations is provided by the construction parameters of the fabric. 
Weft knitted fabrics used in the manufacturing of carpets [33] and plain knitted fabric [34] have been studied. Warp knitting has the advantage of including the same structure up to eight layers of different materials, which allows to the modification of thickness of the structure $[35,36]$.

A woven fabric used without any other structure shows low absorption and can be considered as a porous membrane [37] with an air gap between the fabric and the hard acoustic structure, [38-41] for example, a curtain [42] or other applications including plenum [43-45].

Woven fabrics are used as aesthetic coating of different acoustic materials. In multilayer porous absorbers, the front material has the necessary impedance matching that of air, and the inner layer attenuates the sound weave [46]. In 1991, Yakir Shoshani [47] demonstrated that if a woven fabric of high noise reflection coefficient is joined with a nonwoven of high noise absorption coefficient, the contribution of the fabric to the sound absorption of the ensemble is most significant (20-40\%) in the lower frequency range ( $\mathrm{f}<500 \mathrm{~Hz}$ ). In 2012, Fabien Chevillotte [48] published that a layer based on a woven textile screen can control the sound absorption of a porous multilayer made of an upstream resistive layer of glass screen and a downstream porous material of glass wool. Some patents describe an application comprised of a fabric with a nonwoven $[49,50]$.

According to Soltani and Zerrebini, [37] plain weave fabrics absorb sound better than other weaves due to their higher density, greatest number of yarn inter-sections, shorter freefloat length and severe crimping of yarns in the plain weave. In our project, only plain and its derivative rib weave is used, as this weave provides the highest number of pores per surface unit. Besides this, its shorter free-float length increases the dispersion of the reflected wave and provides the greatest angle of inclination of the side surface for all the threads. This work studies the use of different combinations of a polyester nonwoven and a simple polyester woven fabric for acoustic conditioning. Woven fabrics are commonly added to nonwoven for aesthetics or other reasons. The aim of this paper is focused on the variation a fabric placed on the surface of a nonwoven can produce. We will demonstrate that the fabric acts as a resistive layer on top of the nonwoven and will determine the characteristics for the best combination fabric-nonwoven. The acoustic sound absorption coefficient is measured in a standing wave tube with no air gap behind. The parameters to vary are the thickness of the nonwoven and the fabric ends and picks. This variation will affect the areal density of the fabric. But the main interest of this work is the variation of size of the obtained micro pores and their influence on the sound absorption of the ensemble. Thus, this will allow optimizing the acoustic conditioning by selecting the right distribution of yarns in the fabric by means of its weave and density.

\section{Experimental}

\subsection{Materials}

\section{Nonwoven}

The nonwoven is obtained by the dry-laid method from stapled fibers, with thermal bonding by employing some fibers in the mix with a lower melt point.

Thicknesses of 15,30 and $45 \mathrm{~mm}$ are obtained by overlaying two and three layers of nonwoven, without any gluing method. It is estimated that a total thickness higher than $45 \mathrm{~mm}$ is excessive for a realistic use of the assembly. Likewise, it is considered that the most desirable option relates to the minimum use of materials and the minimum thickness.

\section{Fabric}

The production of fabrics with different warp densities without making any change in the loom setting is achieved by weaving 2, 3, and 4-ply plain weave types with different balance, as shown in Table 2. Once woven, the different plies are separated for study. This makes it possible to obtain fabrics with a variety of warp densities without changing the loom setting. The fabric is comprised of warp and weft, as it is a wave. Warp and weft yarns were made of textured PET polyester. This kind of yarn improves the volume and increases the covering capacity.

The production of fabrics with different warp densities, without making any change in the loom setting, is achieved by weaving 2, 3, and 4-ply plain weave types with different balance. Warp and filling ratio describe how yarns are distributed in each ply, as shown in Table 3. Once woven, the different plies are separated for the study. This made it possible to obtain fabrics with a variety of warp densities without changing the loom setting. The fabric is comprised of warp and weft as it is a wave. Warp and weft yarns were made of textured PET

Table 1. Properties of nonwoven

\begin{tabular}{|c|c|c|c|c|}
\hline Material & $\begin{array}{c}\text { Density } \\
\left(\mathbf{g} / \mathbf{m}^{\mathbf{2}}\right)\end{array}$ & $\begin{array}{c}\text { Thickness } \\
\mathbf{( \mathbf { m m } )}\end{array}$ & $\begin{array}{c}\text { Length of fibers } \\
\mathbf{( \mathbf { m m } )}\end{array}$ & $\begin{array}{c}\text { Linear density of } \\
\mathbf{f i b r e s}(\mathbf{d t e x})\end{array}$ \\
\hline polyester (polyethylene terephthalate, PET) & 160 & 15 & 63 & 12,33 \\
\hline
\end{tabular}

Table 2. Properties of fabric yarns

\begin{tabular}{|c|c|c|c|}
\hline Yarn & Material & Number of filaments & Yarn count (dtex) \\
\hline Warp & polyester (PET) & 40 & 167 \\
\hline Weft & polyester (PET) & 40 & 167 \\
\hline
\end{tabular}


polyester. This kind of yarn improves the volume and increases the covering capacity.

Fabrics were used in the same condition as they were obtained from the loom. No finishing or any other treatment was conducted. The weight in each square meter was studied according to the standard EN 12127: 1998. Textiles. Fabrics. Determination of mass per unit area using small samples. Standard deviation was lower than 4.

\subsection{Methods}

\section{Fabric production}

A Smit GS 900 weaving machine with 9.600 warp yarns and a reed width of $160 \mathrm{~cm}$, controlled by an electronic Jacquard Stäubli DX-100, was used to weave the fabric specimens used in this project. The filling density is electronically controlled.

\section{Sound absorption coefficient}

This research is conducted with the impedance tube method according to the Standard ISO 10534-2: Acoustics. Determination of sound absorption coefficient and impedance in impedance tubes. Transfer function method. In this method, when a sound wave strikes the material perpendicularly, the measured sound absorption coefficient is known as the normal incidence sound absorption coefficient. It requires an impedance tube (between points 1 and 5, as shown in Figure 1), two microphones (see point 2 in Figure 1) and a digital system for the signal treatment (see points 3 and 4 in Figure 1). Figure 1 represents the apparatus used to measure the sound absorption coefficient, consisting of:

1) test sample

2) two microphones (microphones G.R.A.S. model 40AO)

3) data acquisition system (NI-9233)

4) PC

5) sound source

The values represented in this study are an average of the measurements taken three times. Every sample was measured three times for each fabric or for every combination of wovennonwoven.

Plane waves in the tube are generated by a noise source (see point 5 in Figure 1). And, interferential field decomposition is performed by measuring the sound pressure in two positions using microphones hanged on the wall. Then, the complex acoustic transfer function between the two microphones is calculated; this allows the calculation of the complex reflection factor of the sample, from which the absorption coefficient is obtained at normal incidence. Impedance tube is a narrow, rigid and airtight duct which must meet certain characteristics described in the above standard.

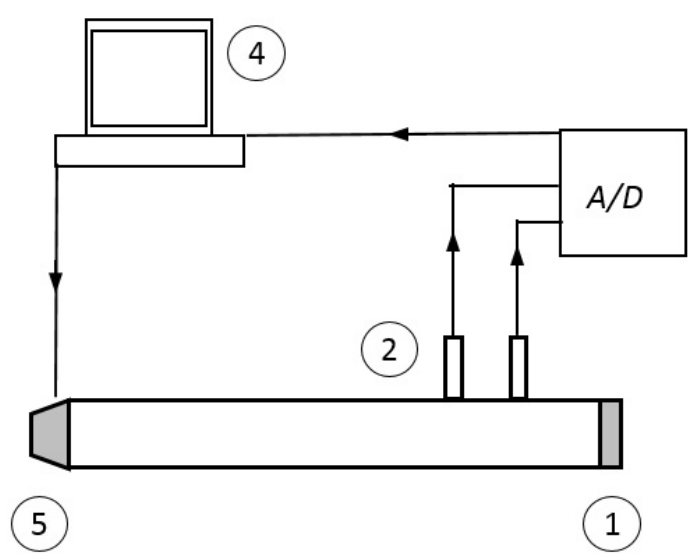

Figure 1. Scheme of the apparatus used to measure the sound absorption coefficient

To perform the test, the sample is placed in one end of the impedance tube (see point 1 in Figure 1). The sample should fit snugly to the sample holder without being compressed or improperly adjusted or being fixed so firmly that it is convex. It is possible to use Vaseline or interstices sealing wax, grease or cover the entire edge. Plane waves are generated in the tube by the sound source (see point 5 in Figure 1), and the pressure in two near positions is measured. Using a Matlab function designed for this purpose, the transfer function - used in this case to calculate the absorption coefficient from normal incidence reflection coefficient - of the complex acoustic signals at two microphones is determined. As explained in the abovementioned ISO 10534-2 standard, this coefficient is determined according to Equation 1:

$$
r=\frac{H_{12}-H i}{H_{R}-H_{12}} \cdot e^{2 \cdot j \cdot k_{0} \cdot x_{1}}
$$

Where:

$r=$ acoustic reflection coefficient

$H 12$ = complex transference function

Table 3. Weaving conditions for obtaining plain fabrics

\begin{tabular}{|c|c|c|c|c|}
\hline Type of weave & Number of plies & Warp ratio & Filling ratio & Resultant weave \\
\hline 1 & 2 & $1 / 1$ & $1 / 1$ & Plain \\
\hline 2 & 2 & $1 / 3$ & $1 / 1$ & Plain and Filling rib \\
\hline 3 & 3 & $1 / 1 / 1$ & $1 / 1 / 1$ & Plain \\
\hline 4 & 3 & $1 / 1 / 2$ & $1 / 1 / 1$ & Plain and Filling rib \\
\hline 5 & 4 & $1 / 1 / 1 / 1$ & $1 / 1 / 1 / 1$ & Plain \\
\hline
\end{tabular}


$H R=$ transference function from the reflected wave

$k 0=$ complex wavenumber

$x 1=$ distance between sample and microphone

After calculating $r$, the sound absorption coefficient for normal incidence $\alpha$ can be obtained by using Equation 2:

$$
\alpha=1-|r|^{2}
$$

\section{Image analysis}

Nahita Zuzi eyepiece video camera USB 1.3 Mp. Programs Minisee was used to observe the fabrics and ScopePhoto 3.1 was used to capture, process and analyze the images. Three different regions of each fabric were photographed. An area of the same size and position was defined. Scopephoto allows adjustments to color and by means of the tool Histogram, all pixels showing a luminosity under 130 are presumed to be pores and the percentage is directly taken from the screen. Standard deviation is lower than 4.

\section{Specific resistance to air flow}

Specific resistance to air flow is determined using the Standard UNE-EN-29053: Materials for acoustical applications; Determination of airflow resistance (ISO 9053). Method: directairflow method. This method consists of passing a slow air stream through a specimen and measuring the pressure loss between the two free sides of the specimen. Measurements are done at 5 different airflow velocities and extrapolation to an airflow velocity of $0.5 \mathrm{~mm} / \mathrm{s}$. Three samples of each combination are measured.

Figure 2. Shows the scheme of the instrument for specific resistance to air flow where:

1 measuring cell inside where the specimen is placed

2 airstream production device

3 air volume flow rate measuring unit

4 differential pressure measuring device from upstream to downstream the specimen

The inner diameter of the cell is $101 \mathrm{~mm}$. The specimen to test (fabric or fabric + nonwoven) is placed on a perforated grid (see label "specimen holder grid" in figure 2) at a height of 850 $\mathrm{mm}$ from the air entrance (at the bottom of the tube in figure 2 ) to allow passage of a laminar and unidirectional air flow through the specimen. A pneumatic compressor is used for the production of airflow compressor (see point 2 in Figure 2). The air flow rate should be less than $0.5 \times 10-3 \mathrm{~m} / \mathrm{s}$.

\section{Results and discussion}

\subsection{Sound absorption from fabrics}

Once the fabric has been woven, they were characterized. Tables 4,5 and 6 summarize the characteristics of the developed fabrics used in the present study, and the different appearance of the fabrics can be noticed. According to

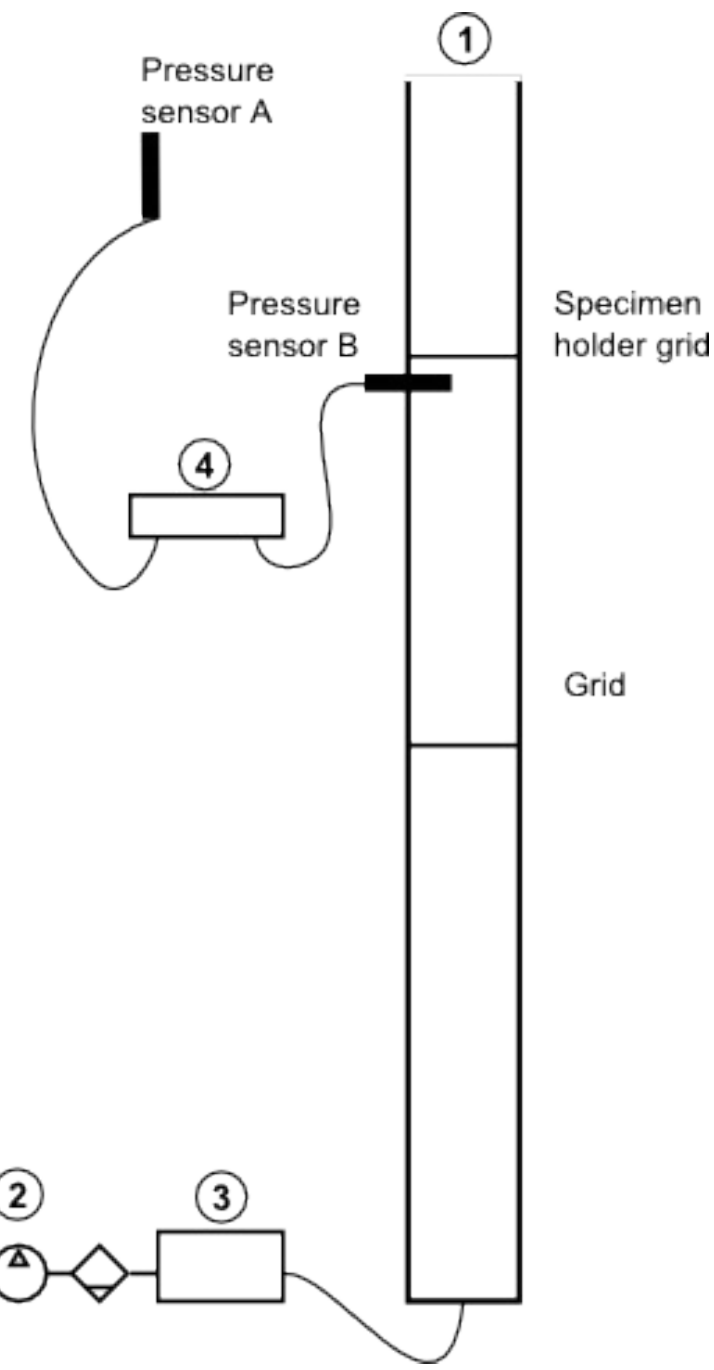

Figure 2. Scheme of the instruments used for specific resistance to air flow

what should be expected, it can be observed that the higher the number of ends or picks, the higher is the areal density $\left(\mathrm{g} / \mathrm{m}^{2}\right)$, and the open area $(\%)$ is slightly reduced. Furthermore, a considerable increase on the resistance to the air flow is appreciable. Figure 3 , shows the fabric with different number of picks and 15 ends, whereas Figure 4 is related with fabrics with 30 ends and Figure 5 shows fabrics with 45 ends.

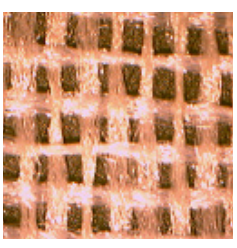

a)

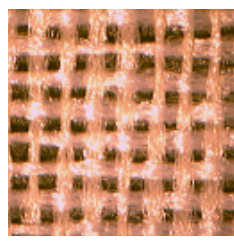

b)

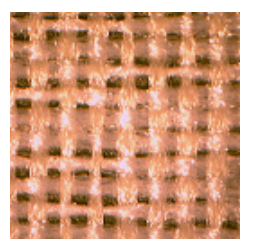

c)
Figure 3. Fabrics with 15 ends. a) 10 picks; b) 15 picks; c) 20 picks

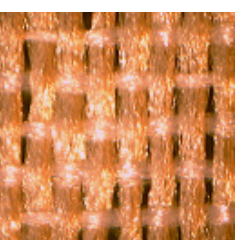

a)

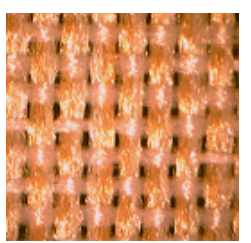

b)

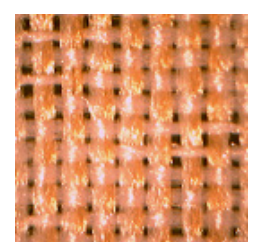

c)
Figure 4. Fabrics with 30 ends. a) 10 picks; b) 15 picks; c) 20 picks 
Table 4. Characteristics of fabrics with 15 warp/cm

\begin{tabular}{|c|c|c|}
\hline & WARP DENSITY (ends/cm) & 15 \\
\hline WEFT DENSITY (picks/cm) & WEAVE & \\
\hline \multirow{4}{*}{10} & NAME & 15end10pick \\
\hline & AREAL DENSITY $\left(\mathrm{g} / \mathrm{m}^{2}\right)$ & 44.05 \\
\hline & OPEN AREA (\%) & 33.25 \\
\hline & $\begin{array}{l}\text { SPECIFIC RESISTANCE TO AIR FLOW } \\
(\mathrm{Pa} \cdot \mathrm{s} / \mathrm{m})\end{array}$ & 10 \\
\hline \multirow{4}{*}{15} & NAME & 15end15pick \\
\hline & AREAL DENSITY $\left(\mathrm{g} / \mathrm{m}^{2}\right)$ & 52.47 \\
\hline & OPEN AREA (\%) & 32.07 \\
\hline & $\begin{array}{l}\text { SPECIFIC RESISTANCE TO AIR FLOW } \\
(\mathrm{Pa} \cdot \mathrm{s} / \mathrm{m})\end{array}$ & 17 \\
\hline \multirow{4}{*}{20} & NAME & 15end20pick \\
\hline & AREAL DENSITY $\left(\mathrm{g} / \mathrm{m}^{2}\right)$ & 61.73 \\
\hline & OPEN AREA (\%) & 31.50 \\
\hline & $\begin{array}{l}\text { SPECIFIC RESISTANCE TO AIR FLOW } \\
(\mathrm{Pa} \cdot \mathrm{s} / \mathrm{m})\end{array}$ & 38 \\
\hline
\end{tabular}

Table 5. Characteristics of fabrics with 30 warp/cm

\begin{tabular}{|c|c|c|}
\hline & WARP DENSITY (ends/cm) & 30 \\
\hline WEFT DENSITY (picks/cm) & WEAVE & \\
\hline \multirow{4}{*}{10} & NAME & 30end10pick \\
\hline & AREAL DENSITY $\left(\mathrm{g} / \mathrm{m}^{2}\right)$ & 71.43 \\
\hline & OPEN AREA (\%) & 30.70 \\
\hline & $\begin{array}{l}\text { SPECIFIC RESISTANCE TO AIR FLOW } \\
\qquad(\mathrm{Pa} \cdot \mathrm{s} / \mathrm{m})\end{array}$ & 56 \\
\hline \multirow{4}{*}{15} & NAME & 30end15pick \\
\hline & AREAL DENSITY $\left(\mathrm{g} / \mathrm{m}^{2}\right)$ & 81.30 \\
\hline & OPEN AREA (\%) & 24.84 \\
\hline & $\begin{array}{l}\text { SPECIFIC RESISTANCE TO AIR FLOW } \\
(\mathrm{Pa} \cdot \mathrm{s} / \mathrm{m})\end{array}$ & 61 \\
\hline \multirow{4}{*}{20} & NAME & 30end20pick \\
\hline & AREAL DENSITY $\left(\mathrm{g} / \mathrm{m}^{2}\right)$ & 90.83 \\
\hline & OPEN AREA (\%) & 20.10 \\
\hline & $\begin{array}{l}\text { SPECIFIC RESISTANCE TO AIR FLOW } \\
(\mathrm{Pa} \cdot \mathrm{s} / \mathrm{m})\end{array}$ & 94 \\
\hline
\end{tabular}

Table 6. Characteristics of fabrics with 45 warp/cm

\begin{tabular}{|c|c|c|}
\hline & WARP DENSITY (ends/cm) & 45 \\
\hline WEFT DENSITY (picks/cm) & WEAVE & \\
\hline \multirow{4}{*}{7,5} & NAME & 45end7.5pick \\
\hline & AREAL DENSITY $\left(\mathrm{g} / \mathrm{m}^{2}\right)$ & 111.82 \\
\hline & OPEN AREA (\%) & $6.106,10$ \\
\hline & $\begin{array}{l}\text { SPECIFIC RESISTANCE TO AIR FLOW } \\
(\mathrm{Pa} \cdot \mathrm{s} / \mathrm{m})\end{array}$ & 99 \\
\hline \multirow{4}{*}{15} & NAME & 45end15pick \\
\hline & AREAL DENSITY $\left(\mathrm{g} / \mathrm{m}^{2}\right)$ & 116.88 \\
\hline & OPEN AREA (\%) & 7.10 \\
\hline & $\begin{array}{l}\text { SPECIFIC RESISTANCE TO AIR FLOW } \\
(\mathrm{Pa} \cdot \mathrm{s} / \mathrm{m})\end{array}$ & 105 \\
\hline \multirow{4}{*}{22,5} & NAME & 45end22,5pick \\
\hline & AREAL DENSITY $\left(\mathrm{g} / \mathrm{m}^{2}\right)$ & 131.15 \\
\hline & OPEN AREA (\%) & 3.5 \\
\hline & $\begin{array}{l}\text { SPECIFIC RESISTANCE TO AIR FLOW } \\
(\mathrm{Pa} \cdot \mathrm{s} / \mathrm{m})\end{array}$ & 155 \\
\hline
\end{tabular}




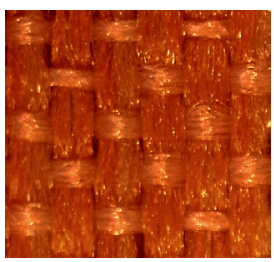

a)

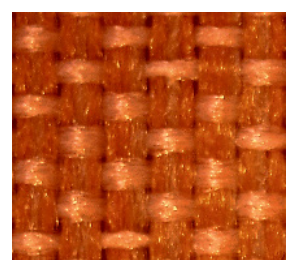

b)

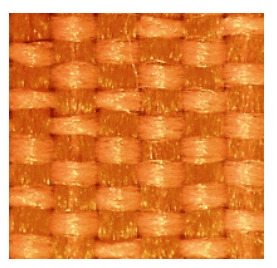

c)
Figure 5. Fabrics with 45 ends. a) 10 picks; b) 15 picks; c) 20 picks

Once the fabrics have been characterized, it is important to establish what the sound wave behavior is when passing throughout the different fabrics and if they can influence the nonwoven absorption. Consequently, the fabrics are placed on top of the nonwoven, the essayed combinations of fabric and nonwoven are as shown in Figure 6:

1) One layer of every fabric is tested one by one (see Figure 6a).

2) One layer of fabric plus one layer of nonwoven, being the fabric layer on the side of the sound source (see Figure $6 \mathrm{~b}, 6 \mathrm{c}$ and $6 \mathrm{~d})$.

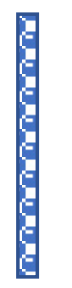

a

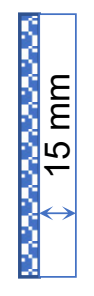

b

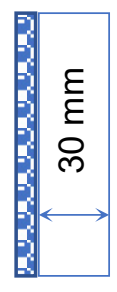

C

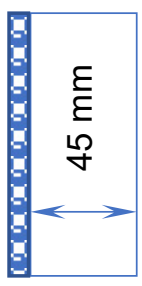

d
Figure 6. Scheme of fabric + nonwoven combinations. a) Fabric, b) Fabric + nonwoven $15 \mathrm{~mm}$ thick. c) Fabric + nonwoven $30 \mathrm{~mm}$ thick. d) Fabric + nonwoven $45 \mathrm{~mm}$ thick

An analysis of variance (ANOVA) is performed to determine if the factors: A - warp density, B - pick density, and C - thickness have a significant effect on the Sound Absorption Coefficient (SAC) of the material. Being all P-values less than 0.05 , the considered factors have significant effects in the absorption of the material at all frequencies, with a $95 \%$ of confidence.

Sound absorption of every fabric was measured. Figures 7 to 9 show results of the absorption coefficient in the range comprised between 400 and $4000 \mathrm{~Hz}$ when the fabric is tested without any nonwoven (see Figure 6a). Plain fabrics with 15, 30 and 45 ends/cm and with weft densities, as shown in Tables 4 , 5 , and 6 , have been studied.

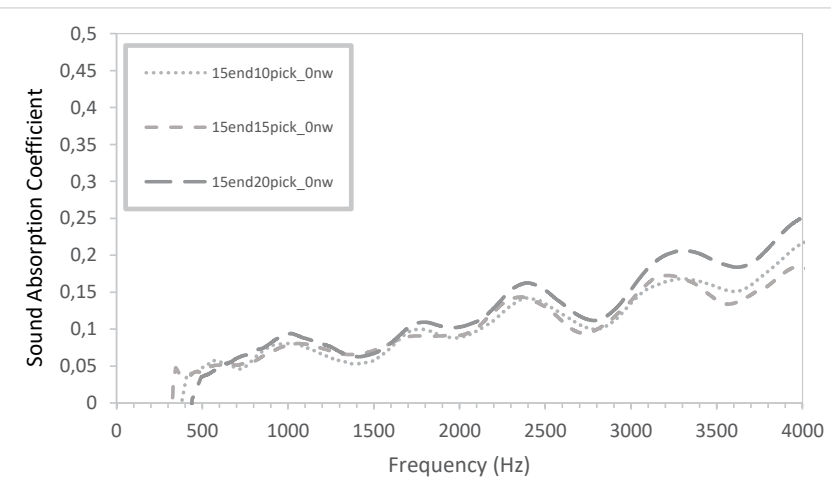

Figure 7. Sound absorption coefficient of 15 ends/cm plain fabrics

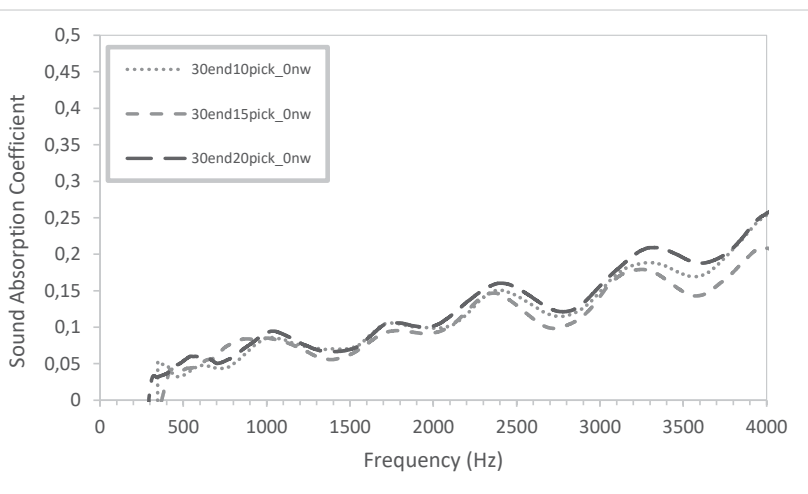

Figure 8. Sound absorption coefficient of 30 ends/cm plain fabrics

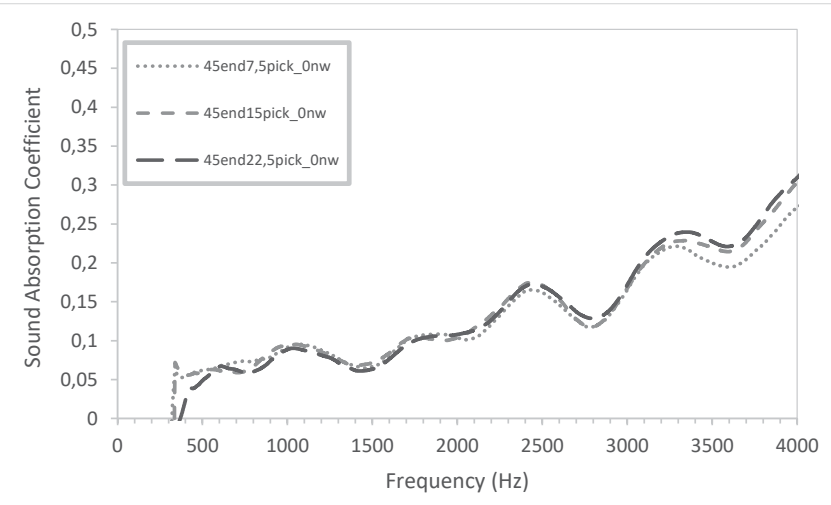

Figure 9. Sound absorption coefficient of 45 ends/cm plain fabrics

It is clearly observed that absorption coefficient is modified by the variation of ends and picks counts. Regardless of the number of ends or picks, sound absorption begins to increase around $1000 \mathrm{~Hz}$ until $4000 \mathrm{~Hz}$. Apart from the region in which the sound absorption begins to increase, a common behavior is appreciated in all the figures (Figures 7-9). Higher the number of picks, higher is the absorption. The highest value is reached when the fabric is comprised of 45 ends $/ \mathrm{cm}$. Thus, as expected, the best fabric is the one made of 45 ends and 22.5 picks.

Nevertheless, if it is desired to obtain a good absorbent material, the absorption coefficient must be higher than 0.5 [51] and it is clearly noticeable that the results showed that the absorption coefficients do not end up reaching those values. Consequently, a nonwoven structure has been added in order to study, such as in study by Chevillotte, [48] if the fabrics can improve the results. Chevillotte studied the influence of a woven screen on a porous multilayer made of glass wool. As mentioned in the introduction, nonwovens are widely used for acoustic purposes. In our case, we choose a simple and conventional nonwoven made of polyester with a low absorption coefficient, which was not considered as an acoustic material in order to combine it with a polyester fabric and to study if results may transform it into a sound absorbing material.

\subsection{Sound absorption including nonwoven.}

Absorption coefficient has been studied for nonwovens of different thickness $(15 \mathrm{~mm}, 30 \mathrm{~mm}$ and $45 \mathrm{~mm}$ ) and even with an empty tube. Figure 10 evidences that there is a resonant effect on the empty tube. Analyzing results considering the 
absorption effect, it can apparently be said that it is only the nonwoven with $45 \mathrm{~mm}$ which shows an absorption coefficient between 0.5 and 0.6 at frequencies higher than $650 \mathrm{~Hz}$. This is because it is not a material specifically designed for sound absorption.

\subsubsection{Fabric and $15 \mathrm{~mm}$ nonwoven thickness}

This part of the test has been conducted with a fabric placed upstream the sound source on a $15 \mathrm{~mm}$ thick nonwoven layer (as a combination shown in Figure 6b). Then, absorption coefficients were measured in the range of frequencies between 400 and $4000 \mathrm{~Hz}$. Three fabrics were used with different ends 15, 30 and 45; results as shown in Figures 11 to 13 respectively.

It is clearly observed from Figures 11-13 that the initial absorption of the nonwoven is modified by the presence of a fabric on its surface.

In Figure 11, we can highlight the 15end30pick fabric that raises the sound absorption coefficient over 0.5 at frequencies around $1623.5 \mathrm{~Hz}$ and higher.

In Figure 12, it is shown how three fabrics with 30 ends/cm and 10,15 and 20 picks/cm have a very similar effect on sound absorption. This means that densities of picks higher than 10 picks $/ \mathrm{cm}$ have no influence on the sound absorption for fabrics with 30 ends.

In Figure 13, fabrics with 45 ends/cm shows a noticeable increase in the absorption when the frequency is higher than $900 \mathrm{~Hz}$. For instance, the 45end22,5pick fabric reaches a sound absorption coefficient of 0.5 at $1060 \mathrm{~Hz}$ and above, reaching a maximum of 0.97 at $2980 \mathrm{~Hz}$.

Another effect of the increase of warp and weft density that is visible in Figure 7 is the decreasing of the frequency at which the maximum absorption is obtained.

\subsubsection{Fabric and $30 \mathrm{~mm}$ nonwoven thickness}

In this part of the text, a second nonwoven is added. Consequently, the distance to the end of the standing tube is doubled to $30 \mathrm{~mm}$ (as combination in Figure 6c) instead of 15 $\mathrm{mm}$, and the fabrics are located on the upper side nearest to the sound source.

As it could be expected, with an increase in the width on the nonwoven, an increase in the absorption coefficient is reached, and the frequency for the maximum absorption is reduced.

In Figure 14, it can be observed that with the fabric 15end30pick, the $30 \mathrm{~mm}$ nonwoven can achieve a sound absorption coefficient over 0.5 from a frequency around 1088 and above. In figures 14, 15 and 16, this value is reached by all the fabrics at lower frequencies than that. For instance, as it could be observed in figure 16, the sample 45end22.5pick plus $30 \mathrm{~mm}$ nonwoven reaches it at $687 \mathrm{~Hz}$, what makes it suitable to be considered as a sound absorber.

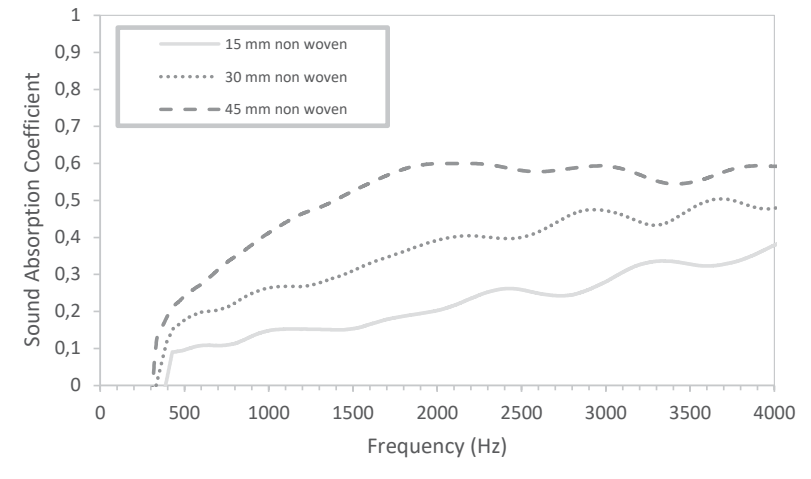

Figure 10. Sound absorption coefficient of the used non-woven at different layer thicknesses

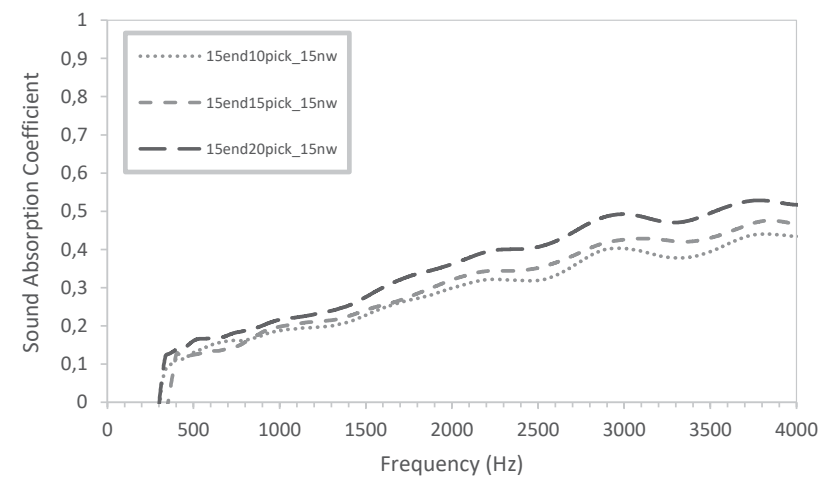

Figure 11. Sound absorption coefficient of 15 ends/cm plain fabrics added to a $15 \mathrm{~mm}$ non-woven layer

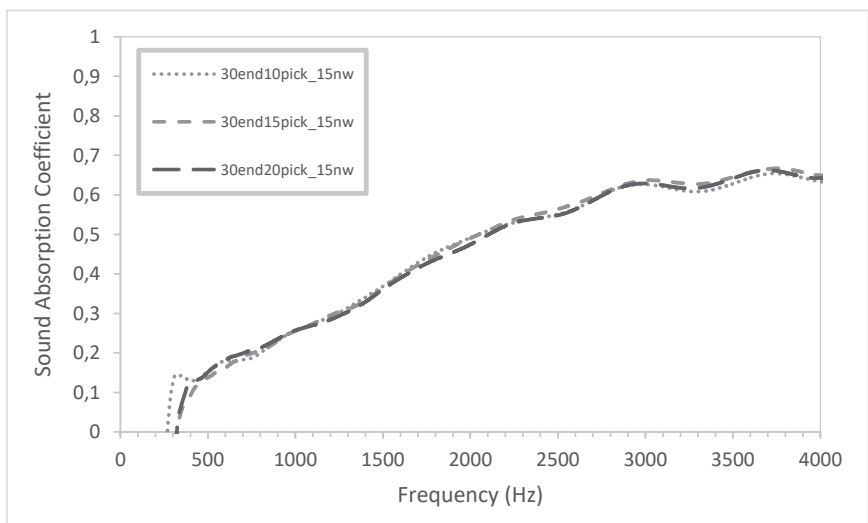

Figure 12. Sound absorption coefficient of 30 ends/cm plain fabrics added to a $15 \mathrm{~mm}$ non-woven layer

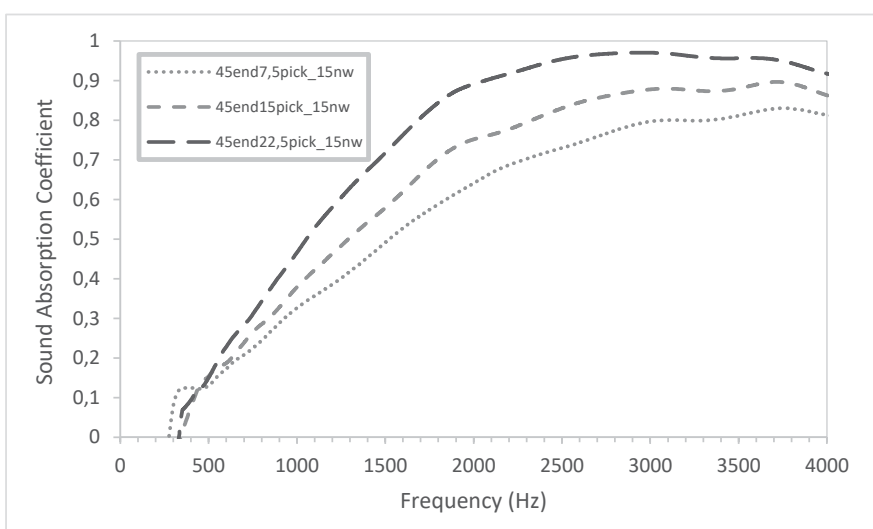

Figure 13. Sound absorption coefficient of 45 ends/cm plain fabrics added to a $15 \mathrm{~mm}$ non-woven layer 


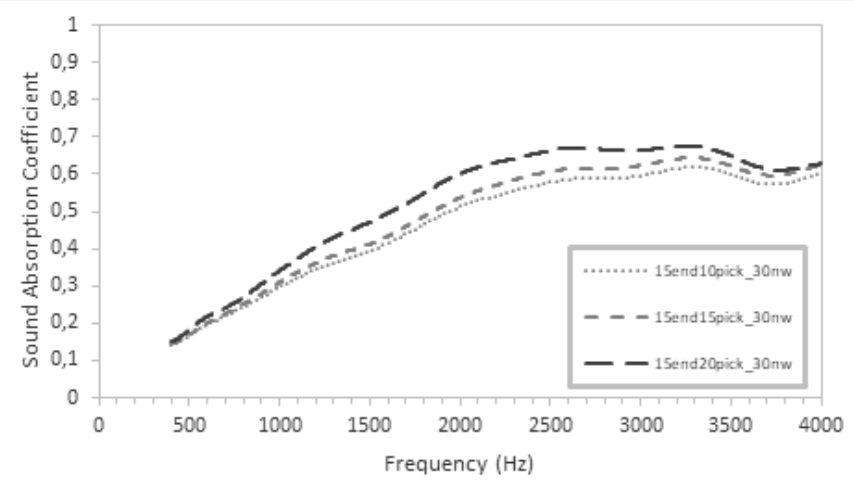

Figure 14. Sound absorption coefficient of 15 ends/cm plain fabrics added to a $30 \mathrm{~mm}$ non-woven layer

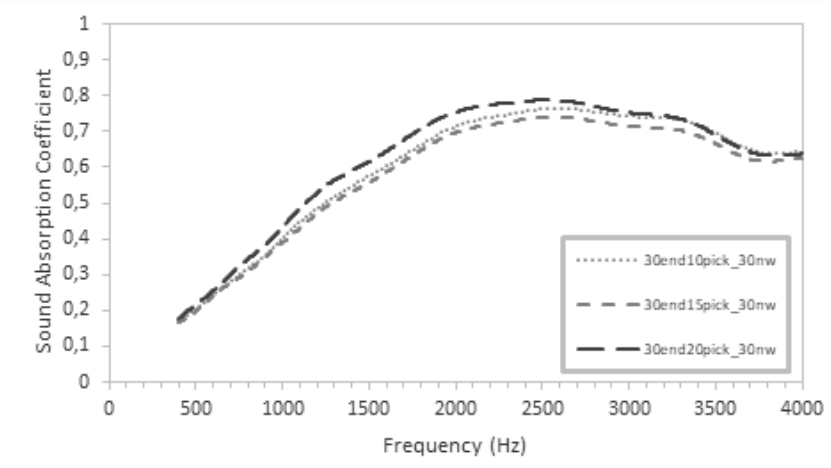

Figure 15. Sound absorption coefficient of 30 ends/cm plain fabrics added to a $30 \mathrm{~mm}$ non-woven layer

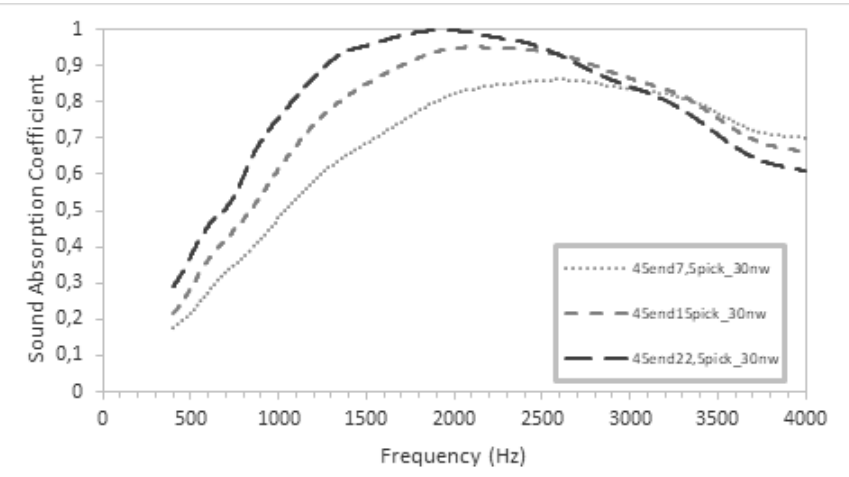

Figure 16. Sound absorption coefficient of 45 ends/cm plain fabrics added to a $30 \mathrm{~mm}$ non-woven layer

When considering the fabric with 15 ends/cm, the one with 20 picks/cm is the one with higher absorption even with one or two nonwovens. However, when two nonwovens are tested (30 $\mathrm{mm}$ ), a considerable absorption at $500 \mathrm{~Hz}$ can be observed if compared with one nonwoven $(15 \mathrm{~mm})$. It should be noted that the fabric with 45 picks $/ \mathrm{cm}$ offers an important increase from $500 \mathrm{~Hz}$.

In Figure 15, we can observe how the 30end10pick fabric added on a $30 \mathrm{~mm}$ nonwoven shows better results than 30 end 15 pick fabric.

\subsubsection{Fabric and $45 \mathrm{~mm}$ nonwoven thickness}

Finally, a third nonwoven is added to obtain $45 \mathrm{~mm}$ width (as combination in Figure 6d). Figures 17, 18 and 19 show results

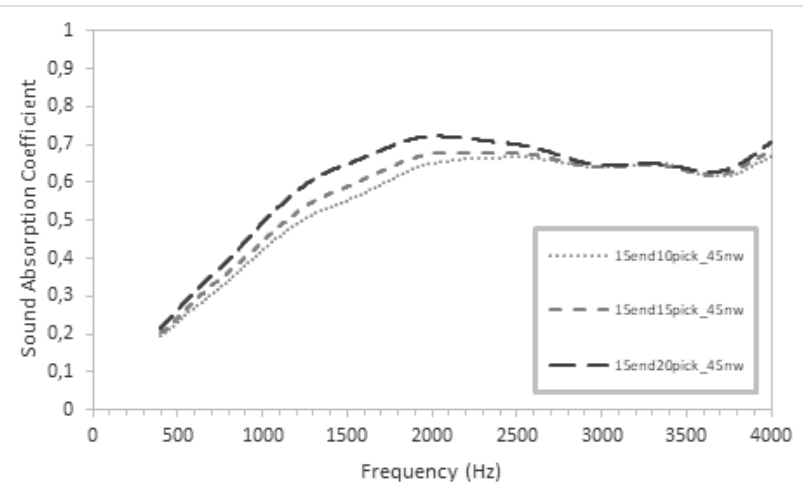

Figure 17. Sound absorption coefficient of 15 ends/cm plain fabrics added to a $45 \mathrm{~mm}$ non-woven layer

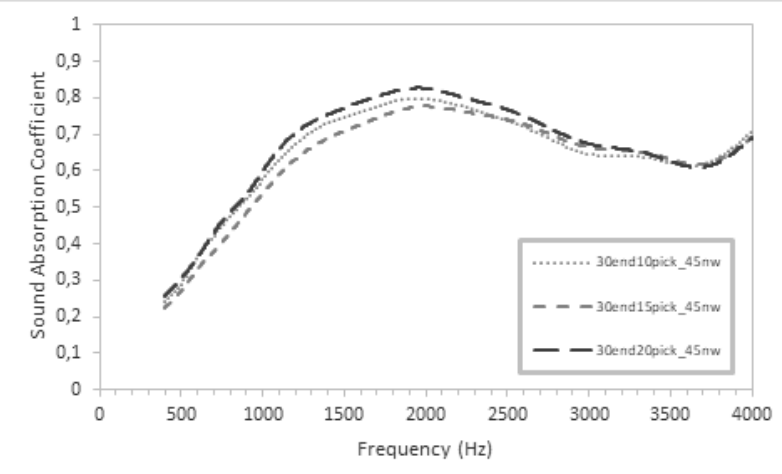

Figure 18. Sound absorption coefficient of 30 ends/cm plain fabrics added to a $45 \mathrm{~mm}$ non-woven layer

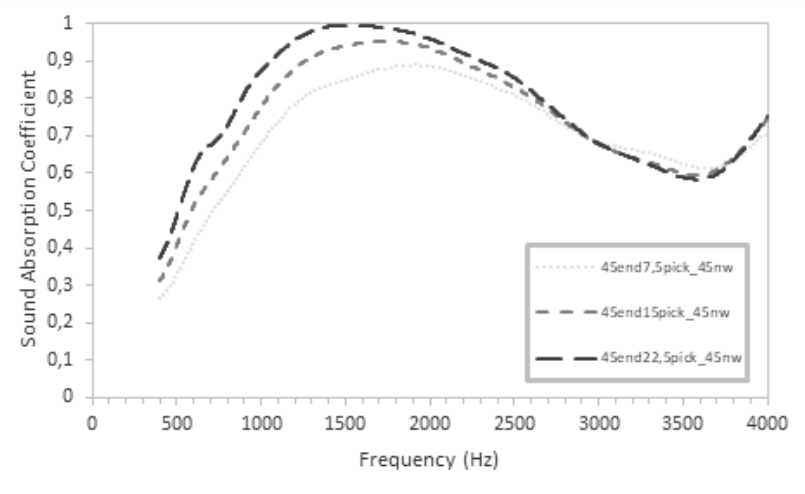

Figure 19. Sound absorption coefficient of 45 ends/cm plain fabrics added to a $45 \mathrm{~mm}$ non-woven layer

for sound absorption when the fabric on the upper surface is made of 15,30 and 45 ends/cm respectively.

Results show that structures with $45 \mathrm{~mm}$ offer significant values for frequencies higher than $500 \mathrm{~Hz}$ for almost every fabric. The worst case is 15end10pick_45NW that reaches this value from $1233 \mathrm{~Hz}$ and above.

In Figure 18, we can observe how the 30end10pick fabric, added on a $45 \mathrm{~mm}$ nonwoven, shows better results than 30end15pick fabric, the gap between all the fabrics is not considerably tough.

When comparing the three figures with 45 ends/cm, regarding the nonwoven thickness (Figure 13 [15 mm], Figure 16 [30 $\mathrm{mm}$ ] and Figure 19 [45 mm]), it can be clearly observed that a 
tendency to decrease the sound absorption is observed at high frequencies, mainly for higher thicknesses.

Moreover, if Figures 12, 15 and 18 are compared, all of them show differences in sound absorption for fabrics with different ends. However, the gap is not so significant between the different fabrics. This could be due to the fact that the number of ends has average value (30 ends). Any change on the number of picks does not alter considerably the pore size and consequently the sound absorption is not modified substantially. Fabrics with 15 or 45 ends will define a rectangle pore size due to the irregular presence of yarns distributed on the warp and eft direction, whereas fabrics with 30 ends, will define a square pore and not many differences are observed.

Analysis form Table 4, 5 and 6 shows how the higher number of ends deals in a reduction in open area and increases the specific resistance to air flow. Table 7 shows the frequencies at which sound absorption coefficient reaches the value 0.5 .

Analysis from Table 7 shows that there is an influence in the number of picks and ends, and the sound absorption. The higher density of yarns in the fabric, the frequencies at which absorption coefficient equals 0.5 , shifts to lower frequencies improving the acoustic.

\section{CONCLUSIONS}

In this manuscript, the sound absorption coefficient has been measured between 400 and $4000 \mathrm{~Hz}$. In order to determine the fabric structure influence, some plain fabric with different warp and weft densities have been located on a nonwoven with different thicknesses (15, 30 and $45 \mathrm{~mm}$ ).

This work agrees with the statements of Cox and D'Antonio [46] that the mass effect of the pores increases the absorption at lower frequencies with the addition of a layer of fabric to a nonwoven. The used fabrics have pores with different sizes and shapes, and thus, with different thermal and viscous effects, they influence the sound propagation in different ways, changing the absorption of the set. The results show an interaction between the nonwoven and the fabric, resulting in an advantageous combination of the thermal effects of the nonwoven and the resonant effects of the fabric. Besides, these effects are present for the three different thicknesses of the nonwoven studied.

It has been proved that there is no significant variation but only a slight variation on the sound absorption coefficient, when they are used without any other structure. However, when combined with nonwovens, the same tendency is observed but the coefficient obtained is higher.

The higher absorptions have been observed for the maximum warp and weft densities studied. When density is increased, two behaviors are observed: On the one hand, the fabric's density is increased. On the other hand, the size and number of pores in the fabric are reduced. Both of these could be the main cause for the variation in the sound absorption coefficient.

When fabrics are used as a resistive layer, a considerable reduction on the frequency of maximum resonance is observed. It decreases from $4000 \mathrm{~Hz}$ for nonwoven with $15 \mathrm{~mm}$ to 500 $\mathrm{Hz}$ in higher density fabrics and $45 \mathrm{~mm}$ of nonwoven. This is partially due to an increase in the distance to the rigid wall, as the width has increased. Nevertheless, when there is no fabric for the same width, the frequency at the maximum absorption is not lower than $800 \mathrm{~Hz}$.

It is remarkable that $45 \mathrm{~mm}$ in width offer important absorptions at low frequencies regardless of the fabric used except the ones with really low densities. Those fabrics with so few densities are so slight that their production is not widely spread, and they are not easy to obtain, though they have been used in the experiment merely to determine the yarn's density influence.

Fabrics with lower densities and thus bigger pores do not modify the absorptive behavior of the nonwoven very much. This is the effect of the variation of characteristics of the fabric. This

Table 7. Frequencies at which sound absorption coefficient equals or exceeds 0.5

\begin{tabular}{|c|c|c|c|}
\hline \multirow{2}{*}{ Fabric } & \multicolumn{3}{|c|}{ Frequencies (Hz) } \\
\cline { 2 - 4 } & 15mm nonwoven & 30mm nonwoven & 45mm nonwoven \\
\hline 15end10pick & Not achieved & $1938-4000$ & $852-4000$ \\
\hline 30end10pick & $2047-4000$ & $1243-4000$ & $1143-4000$ \\
\hline 15end15pick & Not achieved & $1846-4000$ & $929-4000$ \\
\hline 30end15pick & $2051-4000$ & $1284-4000$ & $714-4000$ \\
\hline 45end7,5pick & $1523-4000$ & $1036-4000$ & $586-4000$ \\
\hline 45end15pick & $1291-4000$ & $839-4000$ & $1014-4000$ \\
\hline 15end20pick & $3528-4000$ & $1622-4000$ & $829-4000$ \\
\hline 30end20pick & $2106-4000$ & $1133-4000$ & $510-4000$ \\
\hline 45end22,5pick & $1053-4000$ & $687-4000$ & \\
\hline
\end{tabular}


way we can graphically see the difference in sound absorption caused basically by a variation in the warp and weft densities.

The combination of unequal densities in warp and weft causes the formation of slits instead of square shaped pores. These slits are at two levels: at the weave scale and, as the employed yarn is multifilament, at a filament scale. These filaments can also be considered as small strings that vibrate more easily when the float is longer. This effect is not always present.

Another important practical implication from this study is that there is a considerable advantage in reaching the maximum resonance at lower frequencies when placing the fabric on the top of the nonwoven. This fact is substantially important as the lower frequencies cannot be easily isolated and materials selected in this study are easy to get and not expensive.

The contribution of this findings appears to be considerably important so that future studies would be conducted in order to determine how the structural parameters in a textile fabric could improve the sound absorption efficiency. It can be interesting as textile structures could be considered for acoustic purposes mainly if decoration is an important issue to consider.

\section{References}

[1] Tajadura-Jiménez, A., Larsson, P., Väljamäe, A., Västfjäll, D., \& Kleiner, M., (2010) When room size matters: acoustic influences on emotional responses to sounds. Emotion, 10(3), 416.

[2] Arenas J. P., Crocker, M.J., (2010) Recent trends in porous sound absorbing materials. Sound and Vibration, 13, 44-7.

[3] Lundgren, L., Moberg, C. and Lidén C., (2014). Do insulation products of man $\square$ made vitreous fibres still cause skin discomfort? Contact dermatitis, 70(6), 351-360.

[4] Delany, M.E., Bazley, E.N., (1970). Acoustical properties of fibrous absorbent materials. Applied Acoustics, 3, 105116.

[5] Attenborough, K., (1982). Acoustical Characteristics of Porous Materials. Physics Reports, 82(3), 179-227.

[6] Yang, S., Yu, W., Pan, N., (2010). Investigation of the sound absorbing behavior of fibre assemblies. Textile Research Journal, 81(7), 673-682.

[7] Ramis, J., Alba, J. Del Rey, R., Escuder, E., \& Sanchís, V. J., (2010). New absorbent material acoustic based on kenaf fibre. Materiales de Construcción, 60 (299), 133143.

[8] Chen, Y., Jiang, N., (2007). Carbonized and activated nonwovens as high-performance acoustic materials: Part I - noise absorption. Textile Research Journal, 77, 785-791.

[9] Garai, M., Pompoli, F. A., (2005). Simple empirical model of polyester fibre materials for acoustical applications. Applied Acoustics, 66, 1383-1398.

[10] Narang, P. P., (1995). Material parameter selection in polyester fibre insulation for sound transmission and absorption. Applied Acoustics, 45, 335-358.

[11] M. Küçük, Y. Korkmaz. (2012). The effect of physical parameters on sound absorption properties of natural fibre mixed nonwoven. Textile Research Journal, 82, 20432053.
[12] Labino, D. "Decorative acoustical materials", U.S. Patent 2 868684.1959.

[13] Takewa et al. "Sound absorber", U.S. Patent 5512 715, 1996.

[14] Fox, A. R., Olson, D. A., Moore, E. M., Berrigan, M. R., Nelson, D. L., Eaton, B. W., \& Mahoney, W. S. "Multilayer articles having acoustical absorbance properties and methods of making and using the same". U.S. Patent 7757 811 B2, 20-07. 2010. Also published as: EP1945445A1, EP1945445A4, US7691168, US20080230309, US20100043639 y WO2007047263A1

[15] Ogawa, M., Fujii, M., \& Mizutani, N. "Sound absorbing material, multilayer sound absorbing material, molded product of multilayer sound absorbing material, sound absorbing interior material, and sound absorbing floor covering material" U.S. Patent 8393438 B2, 2013. Also published as: B2CA2739408A1, CN102089802A, EP2333766A1, EP2333766A4, EP2333766B1, US20110186381, WO2010038486A1, WO2010038491A1,

[16] Zwikker, C., Kosten, C. (1949). Sound Absorbing Materials. Elsevier, Nueva York. cap.II.

[17] Benarek, L.L., (1971). Noise and Vibration Control. Mc Graw Hill, New York, p. 267.

[18] Maa, D. Y., (1975). Theory and design of microperforated panel sound-absorbing constructions. Scentia Sinica,17, 55-71.

[19] Ruiz, H., Cobo, P., \& Jacobsen, F. (2011). Optimization of multiple-layer microperforated panels by simulated annealing. Applied Acoustics, 72, 772-776.

[20] Sakagami, K. Sakagami, K., Kobatake, S., Kano, K. I., Morimoto, M., \& Yairi, M. (2011). Sound absorption characteristics of a single microperforated panel absorber backed by a porous absorbent layer. Acoustics Australia, 39(3), 95-100.

[21] Maa, D.Y., (1998). Potential of microperforated panel absorbers. Journal of Acoustical Society of America, 104, 2861-2866

[22] Pfretzschner, J. et al. (2006). Microperforated insertion units: an alternative strategy to design microperforated panels. Applied Acoustics, 67, 62-73.

[23] Cobo, P., Pfretzschner, J., Cuesta, M., \& Anthony, D. K. (2004). Hybrid passive-active absorption using microperforated panels. Journal of Acoustical Society of America, 116, 2118-2125.

[24] Lui, J., Herrin, D.W., (2010). Enhancing micro-perforated panel attenuation by partitioning the adjoining cavity. Applied Acoustics, 71.2, 120-127.

[25] Takahashi, D., Tanaka, M., (2002). Flexural vibration of perforated plates and porous elastic materials under acoustic loading. Journal of Acoustical Society of America, 112, 1456-1464.

[26] Lee, Y. Y., Lee, E. W. M., \& Ng, C. F. (2005). Sound Absortion of a finite flexible micro-perforated panel backed by an air cavity. Journal of Sound and Vibration, 287, 227243.

[27] Bravo, T., Maury, C., Pinhède, C., (2012) Vibroacoustic properties of thin micro-perforated panel absorbers. Journal of Acoustical Society of America, 132 (2), 789-798.

[28] Li, G., Mechefske, C.K., (2010). A comprehensive experimental study of micro-perforated panel. Magnetic Resonance Materials in Physics, Biology and Medicine. 23,177-185. 
[29] Fuchs, H. et al. Fuchs, H., \& Zha, X. "Sound absorbing glass building component or transparent synthetic glass building component", U.S. Patent 5700527 A, 1997.

[30] Wood, K.H., Martinson, P.A., "Shaped microperforated polymeric film sound absorbers and methods of manufacturing the same", U.S. Patent 6598701 B1, 29.07.2003. Also published as EP1295282A1, WO2002003375A1.

[31] Pfretzeschner, J., Cobo, P., "Insertion units which are microperforated for use as sound absorbers". WO 2006021605 A1.

[32] Vigran, T.E. Petersen O. "Sound Absorbent". Solicitud U. S. Patent 20080264720 A1, 2005. Also published as: CA2602301A1, EP1861554A1, EP1861554A4, US7677359, y WO2006101403A1.

[33] Shoshani, Y., Wilding, M. A., (1991). Effect of pile parameters on the noise absorption capacity of tufted carpets. Textile Research Journal, 736, 736-742.

[34] Dias, T., Monaragala, R., (2006). Sound absorption in knitted structures for interior noise reduction in automobiles. Measurement Science Technology, 17, 2499-2505

[35] Dias, T., Monaragala, R., Lay, E., (2007). Analysis of thick spacer fabrics to reduce automobile interior noise Measurement Science Technology, 18, 1979-1991.

[36] Liu, J., Hu, H. (2010). Sound Absorption Behavior of Knitted Spacer Fabrics. Textile Research Journal, 80(18), 1949-1957.

[37] Soltani, P., Zerrebini, M. (2012). The analysis of acoustical characteristics and sound absorption coefficient of woven fabrics. Textile Research Journal, 82, 875-882.

[38] Shoshani, Y., Rosenhouse, G. (1990). Noise absorption by woven fabrics. Applied Acoustics. 30, 321-333.

[39] Kang, J., Fuchs, H.V. (1999). Predicting the absorption of open wave textiles and micro-perforated membranes backed by an air space. Journal of Sound and Vibration, 220(5), 905-920.
[40] Pieren, R. (2012). Sound absorption modeling of thin woven fabrics backed by an air cavity. Textile Research Journal, 82, 864-874.

[41] Villamil, H. L. R., Cobo, P., Dupont, T., \& Leclaire, P. (2012). Acoustic properties of perforated plates and screens, in Proceedings of the Acoustics. Nantes Conference. Nantes, France; 2012, April 23-27.

[42] Hanna, Y.I., Kandil, M.M. (1991). Sound absorbing double curtains from local textile materials. Applied Acoustics, 34, 281-291

[43] Mouraret, D.; Tisseyre, A. "Sound absorbing fabric", US 7 976946 - B2, 2011.

[44] Nonogi M., SASAKI M. NORO T. "Multilayer sound absorbing structure comprising mesh layer", U. S. Patent 8 573358 B2, 2013.

[45] Sahnoune, F. "Nappe textile capable a absorber des ondes sonores", WO Patent 2013/007908 2013

[46] Cox, T. J., D’Antonio, P. (2009). Acoustic Absorbers and Diffusers: Theory, Design and Application. Taylor and Francis, New York.

[47] Shoshani, Y. K. (1991). Noise absorption by a combination of woven and nonwoven fabrics. Journal of Textile Institute, 82, 500-503

[48] Chevillote F. (2013). Controlling sound absorption by an upstream resistive layer. Applied Acoustics. 73, 56-60.

[49] Kitchen, D.S. "Acoustically coupled non-woven composite". U.S. Patent 8322487 B1, 4. 12. 2012.

[50] Coates, M.W., Kierzkowski M.H., Gibbons P.J., et al. "Sound absorption material and method of manufacturing sound absorption material". U.S. Patent 8365862 B2, 05.02.2013. Published as EP2297412A4, US20110139543, US20130192921, WO2009140713A1

[51] Crocker, M. J. "Handbook of acoustics". John Wiley \& Sons, 1998. 
AUTEX Research Journal, Vol. 18, No 3, September 2018, DOI: 10.1515/aut-2018-0006 ๔ AUTEX 